\title{
Examining Material Hardship in Mothers: Associations of Diaper Need and Food Insufficiency with Maternal Depressive Symptoms
}

\author{
Anna E. Austin ${ }^{1,2, *}$ and Megan V. Smith ${ }^{1,3,4}$
}

\begin{abstract}
Objectives: Material hardship represents a potential mechanism by which poverty influences the mental health of mothers. This study examined the association between two forms of material hardship, diaper need and food insufficiency, and maternal depressive symptoms.

Methods: Data were from a cross-sectional study of 296 urban, pregnant or parenting, low-income women. A linear regression model was used to examine the association of maternal depressive symptoms, measured by the Center for Epidemiologic Studies Depression (CES-D) score, with diaper need and food insufficiency, after adjustment for demographic factors.

Results: More than half of women reported diaper need (50.3\%) and food insufficiency (54.7\%). Nearly one-third of women who reported diaper need did not report food insufficiency (32.2\%). In bivariate analyses, diaper need and food insufficiency were associated with maternal CES-D score. In multivariate analyses, women who reported diaper need had a significantly higher CES-D score than women who did not report diaper need $(\beta=3.5, p=0.03)$. Women who reported food insufficiency did not have a significantly higher CES-D score than women who did not report food insufficiency $(\beta=2.4, p=0.15)$.

Conclusions: Diaper need is a form of material hardship that has received little attention in the research literature. Diapers, unlike food, are currently not an allowable expense in U.S. antipoverty programs. Diaper need may contribute to maternal depressive symptoms, beyond the contribution of other forms of material hardship, because there are no supports in place to provide assistance meeting this basic need. Importantly, diaper need is a malleable factor amenable to public health and policy interventions.
\end{abstract}

Keywords: material hardship; poverty; mental health; maternal health; child health

\section{Introduction}

In the United States, $14.8 \%$ of individuals live in poverty. ${ }^{1}$ Estimates consistently show that racial and ethnic minorities, women, children, and families headed by single women are particularly vulnerable to poverty. ${ }^{2}$ Poverty is a well-established risk factor in the etiology of a number of mental disorders with studies consistently demonstrating an association between low-socioeconomic status and increased risk for poor mental health., ${ }^{3,4}$ Research suggests that mothers with young children living in poverty are at a particularly increased risk of depression. Among low-income mothers of young children in the U.S. results from several community-based studies estimate the prevalence of clinically significant depression to be between $16 \%$ and $48 \%$, depending on the sample and measurement of depression. ${ }^{5-10}$

\footnotetext{
${ }^{1}$ Department of Psychiatry, Yale University School of Medicine, New Haven, Connecticut.

${ }^{2}$ Department of Maternal and Child Health, University of North Carolina at Chapel Hill Gillings School of Global Public Health, Chapel Hill, North Carolina.

${ }^{3}$ Child Study Center, Yale University School of Medicine, New Haven, Connecticut.

${ }^{4}$ Department of Chronic Disease Epidemiology, Yale School of Public Health, New Haven, Connecticut.

*Address correspondence to: Anna E. Austin, MPH, Department of Psychiatry, Yale University School of Medicine, 300 George Street, 9th Floor, Suite 9B, New Haven, CT 06510, E-mail: anna.austin@unc.edu
}

(c) Anna E. Austin and Megan V. Smith 2017; Published by Mary Ann Liebert, Inc. This is an Open Access article distributed under the terms of the Creative Commons Attribution License, which permits unrestricted use, distribution, and reproduction in any medium, provided the original work is properly cited. 
A growing body of evidence suggests that it is not only the experience of living with low income but also material hardship, including lack of basic needs, that influences parental stress and mental illness. ${ }^{11-14}$ Previous research regarding the association between poverty and poor mental health has relied on use of traditional measures of poverty and socioeconomic status such as income, education, and employment status. Recent research has begun to focus on the concept of material hardship and ways in which to capture the concrete deprivations and daily stressors associated with poverty. ${ }^{15}$ For example, a recent longitudinal study examined the association between the number of economic hardships reported in the past 12 months (not paying the full amount of rent, not paying the full amount of gas/oil/electricity bill, receiving free food/ meals, and not being able to go to the doctor because of cost) and the likelihood of depression among mothers with young children. Results demonstrated an increased risk of depression with a greater number of material hardships reported. ${ }^{15}$ Additional longitudinal studies suggest that such measures of material hardship mediate most, but not all, of the relationship between poverty and depression among mothers with young children. ${ }^{12}$ These findings are meaningful as measures of material hardship are modifiable and provide a clear direction for public health and policy interventions aimed at improving maternal mental health.

\section{Food insufficiency and maternal mental health}

Food insufficiency is a commonly cited form of material hardship with several studies indicating that food insufficiency is strongly associated with poor mental health among low-income women and mothers. ${ }^{16,17}$ In a prospective study of U.S. women who were welfare recipients, changes in food insufficiency, defined as sometimes or often not having enough food in the household, were strongly associated with changes in depressive symptoms such that food insufficiency was related to higher depressive symptom scores. ${ }^{16}$ Among very poor African American mothers, food insufficiency was shown to increase risk for depression even after adjustment for several other risk and protective factors such as lack of employment, housing deterioration, availability of childcare and transportation, and racial discrimination. ${ }^{17}$ Such findings indicate that food insufficiency may function as a contributing factor to mental disorders in this population, ${ }^{16,17}$ although mediating and moderating mechanisms remain unclear.

\section{Diaper need and maternal mental health}

Diaper need, defined as an inadequate supply of diapers to change a child as often as needed, is a basic need specific to caregivers and children. ${ }^{18}$ Until recently, diaper need has received relatively little attention in the research literature or public health agenda. In 2013, the first peer-reviewed article to quantify diaper need and the associated mental health consequences among low-income mothers in the U.S. was published. This study found that $30 \%$ of mothers reported diaper need and that diaper need was significantly associated with high levels of self-reported mental distress in mothers. ${ }^{18}$ A previous study funded by a large diaper manufacturer found that one in three U.S. and Canadian mothers reported diaper need. Mothers with diaper need were more likely to be living in poverty or to suffer from financial hardship than those without diaper need. In addition, mothers with diaper need reported emotional consequences related to being unable to change their child's soiled diaper such as anxiety, guilt, frustration, and feeling like a bad mother. ${ }^{19}$ Results from these studies indicate that diaper need may adversely affect the mental health of low-income women by causing negative emotions. Like other forms of material hardship, diaper need may operate as an independent contributing factor to poor mental health among low-income women and, as a potentially modifiable risk factor, suggest tangible means for public health and policy interventions.

The aim of this study was to examine the association of two forms of material hardship, diaper need and food insufficiency, with depressive symptoms among an urban sample of low-income, pregnant or parenting women.

\section{Materials and Methods}

Data for this study were derived from a cross-sectional study conducted as part of the New Haven Mental Health Outreach for Mothers (MOMS) Partnership. The MOMS Partnership is a community-academic partnership between a Northeastern academic medical center, community partner agencies, and mothers. The MOMS Partnership mission is to ensure the emotional health of families, with a primary target of low-income mothers.

\section{Recruitment and assessment}

MOMS Partnership Community Mental Health Ambassadors (CMHAs) recruited women across New Haven, $\mathrm{CT}$, to participate in a needs assessment consisting of 
questions drawn from standard health surveys (20\%) and questions created through a community partnership model (80\%). CMHAs were New Haven mothers hired for their familiarity with local neighborhoods and trained in brief mental health outreach and participant engagement. Women were eligible to complete the needs assessment if they spoke English or Spanish, provided written informed consent, were pregnant or the mother (biological or adoptive) of a child under the age of 18 years, and lived in the City of New Haven. Systematic efforts, including coordination with local organizations, were made to conduct outreach evenly across low-income neighborhoods in New Haven and at places where families live (public housing), learn (schools, early childhood learning centers, and adult education centers), interact (bus stops, hair and beauty salons, grocery stores, churches, and libraries), and play (playgrounds, parks, and fairs). CMHAs approached potential participants and requested their time to complete the needs assessment. The average interview lasted $35 \mathrm{~min}$, and mothers received compensation in the form of a $\$ 10$ gift card for participation. The majority of needs assessments were completed by women as self-report (70\%); however, CMHAs read the questionnaires to women who either requested it or demonstrated difficulty reading or interpreting the questions. Procedures for data collection and analysis were approved by the Yale University Institutional Review Board (IRB) and IRBs at participating agencies where applicable.

\section{Measures}

Demographics. Demographic factors included selfreported race/ethnicity, age, number of children under 18 years living in the household, and whether the mother had ever taken part in the Supplemental Nutrition Assistance Program (SNAP), Temporary Assistance for Needy Families (TANF), or Women, Infants, and Children (WIC).

Maternal depressive symptoms and trauma history. Maternal depressive symptoms were assessed using the Center for Epidemiologic Studies Depression (CES-D) scale. The CES-D scale was developed to measure depressive symptoms in the general population and has been widely used in epidemiological and psychological research. The CES-D questionnaire consists of 20 questions regarding depressive symptoms. Questions are rated from 0 to 3 , with 0 indicating that the symptom was experienced rarely or not at all during the past week and 3 indicating that the symptom was experienced most or all of the time during the past week. CES-D scores range from 0 to 60 . Previous research suggests that scores of 16 or greater are indicative of elevated levels of depressive symptoms. The reliability and validity of the CES-D scale have been demonstrated in community samples. ${ }^{20}$

Adverse childhood experiences. The adverse childhood experiences (ACEs) score is a standardized score that measures cumulative exposure to traumatic childhood events. ${ }^{21}$ ACEs were assessed by asking mothers whether, as a child, they had experienced emotional, physical, or sexual abuse, adult mental illness, substance abuse, or domestic violence in the household, incarceration of a family member, or the absence of both biological parents. The ACE score is a count of the total number of events experienced. Scores range from 0 to 8 .

Diaper need. Diaper need was assessed with the question, "If you have children in diapers, do you ever feel that you do not have enough diapers to change them as often as you would like?" Women who responded "yes" were then asked what they do when they do not have enough diapers. Response choices included: borrow diapers or money from family or friends, get diapers from an agency, stretch the diapers I have, and other. Women who responded "yes," they do not have enough diapers to change their children as often as they would like or indicated they use one or more of the mentioned methods to obtain diapers were considered to report diaper need. Women who responded "no," they feel they do have enough diapers to change their children as often as they would like and did not indicate that they use any of the mentioned methods to obtain diapers were considered to report no diaper need. Women who responded either "yes" or "no" to the question, "If you have children in diapers, do you ever feel that you do not have enough diapers to change them as often as you would like?" but indicated they did not have children 3 years and under were recoded as missing.

Food insufficiency. Food insufficiency was assessed with the question, "Does your family ever run out of food before the end of the month?" Women who responded "yes" were then asked what they do when they run out of food before the end of the month. Response choices included: borrow food or money 
from family or friends, use a food bank, go to a soup kitchen, we go without, and other. Women who responded "yes," they run out of food before the end of the month or indicated they use one or more of the mentioned methods to obtain food were considered to report food insufficiency. Women who responded "no," they do not run out of food before the end of the month and did not indicate that they use any of the mentioned methods to obtain food were considered to report no food insufficiency. The term food insufficiency was chosen as established measures of food insecurity such as the U.S. Household Food Security Survey module capture additional facets of this basic need including the nutritional quality of the food. ${ }^{22}$

\section{Statistical methods}

The final analytic sample included women who completed the MOMS Partnership needs assessment and had at least one young child age 3 years or under in diapers $(n=296)$. Sample characteristics were examined using descriptive statistics, and bivariate analyses were conducted using $t$-tests to examine unadjusted associations between CES-D score, diaper need, and food insufficiency. A linear regression model was constructed using CES-D score as the dependent variable, diaper need and food insufficiency as the primary independent variables, and demographic variables with significant bivariate associations with CES-D score or theoretical plausibility as covariates. Covariates included age, race, number of children under age 18 years living in the household, and ACE score. Missing data were excluded from the model. All data were analyzed in $\mathrm{SAS}^{\circledR}$ version 9.3 (SAS Institute, Inc., Cary, NC).

\section{Results}

\section{Sample characteristics}

Descriptive characteristics of the sample $(n=296)$ are given in Table 1 . The majority of women were African American (56.5\%) or Hispanic $(23.3 \%)$ with a mean age of 33.2 years $(S D=10.6)$. The average number of children under 18 years in the household was $2.0(\mathrm{SD}=1.2)$. The sample represented primarily lowincome women with $91.9 \%$ having taken part in SNAP, TANF, or WIC (data not shown). Over half of women $(54.7 \%)$ reported food insufficiency and diaper need (50.3\%). A total of 101 women reported both food insufficiency and diaper need (34.1\%). Nearly onethird of women $(32.2 \%)$ who reported diaper need did not report food insufficiency. The mean CES-D
Table 1. Sample Characteristics $(n=296)$

\begin{tabular}{lc}
\hline Characteristic & \\
\hline Race/ethnicity, $n(\%)$ & \\
$\quad$ African American & $176(56.5)$ \\
Hispanic & $69(23.3)$ \\
$\quad$ White/other & $43(14.5)$ \\
Number of children under 18 in household, mean (SD) & $2.0(1.2)$ \\
Age (years), mean (SD) & $33.2(10.6)$ \\
Food insufficiency, $n$ (\%) & \\
$\quad$ Yes & $162(54.7)$ \\
$\quad$ No & $128(43.2)$ \\
Diaper need, $n$ (\%) & \\
$\quad$ Yes & $149(50.3)$ \\
$\quad$ No & $147(49.6)$ \\
ACE score, mean (SD) & $1.4(1.9)$ \\
Depressive symptoms (CES-D score), mean (SD) & $19.8(11.3)$
\end{tabular}

Percentages may not sum to $100 \%$ due to missing values. ACE, adverse childhood experience; CES-D, Center for Epidemiologic Studies Depression; SD, standard deviation.

score was $19.8(\mathrm{SD}=11.3)$. The percentage of women with a CES-D score of 16 or greater, the threshold commonly used to indicate elevated levels of depressive symptoms, was similar among women who reported diaper need and food insufficiency (68.3\%), women who reported diaper need but not food insufficiency $(62.0 \%)$, and women who reported food insufficiency but not diaper need (65.6\%). The percentage was lower among women who did not report either diaper need or food insufficiency (47.0\%; data not shown).

\section{Bivariate analysis}

Bivariate analyses examining associations between maternal depressive symptoms, diaper need, and food insufficiency are presented in Table 2. In bivariate analyses, maternal depressive symptoms were significantly associated with both diaper need and food insufficiency. The mean CES-D score for women who reported diaper need was $21.9(\mathrm{SD}=11.5)$ compared with $17.8(\mathrm{SD}=10.8)$ for women who did not report diaper need. Similarly, the mean CES-D score for women who reported food insufficiency was $21.8(\mathrm{SD}=11.7)$

\begin{tabular}{|c|c|c|}
\hline Variable & CES-D score, mean (SD) & $p$ \\
\hline Food insufficiency & & 0.002 \\
\hline Yes & $21.8(11.7)$ & \\
\hline No & $17.5(10.5)$ & \\
\hline \multicolumn{3}{|l|}{ Diaper need } \\
\hline Yes & $21.9(11.5)$ & 0.002 \\
\hline No & $17.8(10.8)$ & \\
\hline
\end{tabular}


compared with $17.5(\mathrm{SD}=10.5)$ for women who did not report food insufficiency.

\section{Multivariate analysis}

Results from the linear regression model are presented in Table 3. After adjustment for race, number of children under age 18 years living in the household, age, and ACE score, women who reported diaper need had a significantly higher CES-D score than women who did not report diaper need $(\beta=3.5, p=0.03)$. Women who reported food insufficiency did not have a significantly higher CES-D score than women who did not report food insufficiency $(\beta=2.4, p=0.15)$.

\section{Discussion}

The aim of this study was to examine the association between two forms of material hardship, food insufficiency and diaper need, and maternal depressive symptoms among a sample of low-income, racially and ethnically diverse pregnant and parenting women. Diaper need and food insufficiency both represent a form of material hardship and a potential pathway by which poverty affects maternal mental health. In our sample, over half of women reported diaper need and over half reported food insufficiency. Nearly two-thirds reported both diaper need and food insufficiency. The average CES-D score was 19.8, well above the threshold score of 16 used to indicate elevated levels of depressive symptoms.

In all analyses, mothers who reported they did not have enough diapers to change their children as often as needed had a significantly higher CES-D score than those who reported they generally had an adequate supply of diapers. These results support findings from a previous study that found that women who reported trouble managing stress, sadness, or trauma

Table 3. Adjusted Associations Between Maternal Depressive Symptoms and Diaper Need, Food Insufficiency, and Demographic Variables $(n=211)$

\begin{tabular}{lcc}
\hline Variable & $\begin{array}{c}\text { Parameter } \\
\text { estimate (SE) }\end{array}$ & $\boldsymbol{p}$ \\
\hline Diaper need & $3.54(1.6)$ & 0.03 \\
Food insufficiency & $2.4(1.7)$ & 0.15 \\
Race/ethnicity & & \\
$\quad$ African American (reference) & - & - \\
Hispanic & $4.3(1.8)$ & 0.01 \\
$\quad$ White & $-1.6(2.1)$ & 0.44 \\
Number of children under 18 in household & $-0.16(0.6)$ & 0.81 \\
Age & $0.04(0.07)$ & 0.6 \\
ACE score & $1.7(0.4)$ & $<0.0001$ \\
\hline
\end{tabular}

$\mathrm{SE}$, standard error. were more likely to report diaper need than women who did not report such emotional difficulties. ${ }^{18} \mathrm{An}$ inadequate supply of diapers may negatively affect the mental health of low-income mothers by increasing parenting stress and creating a reduced sense of parenting competency. The association between diaper need and maternal mental health has important implications not only for maternal well-being but also for child development. The effect of increased maternal stress and depression on child development, the mother-child relationship, and the risk of child social, emotional, and behavioral problems is documented in the research literature. ${ }^{23-26}$ Failure to provide adequate diaper changes has also been linked to the development of urinary tract infections and diaper dermatitis in young children. ${ }^{27,28}$

In unadjusted analyses, both diaper need and food insufficiency were significantly associated with a higher CES-D score. In the final linear regression model, only diaper need was found to be significantly associated with a higher CES-D score, after controlling for demographic factors and food insufficiency. Diapers, unlike food, are currently not an allowable expense in U.S. antipoverty programs, including TANF and WIC. Disposable diapers cost $\$ 70-\$ 80$ per month per child, representing a substantial financial burden. ${ }^{29}$ Diaper need may affect maternal depressive symptoms, even after accounting for other forms of material hardship such as food insufficiency, because there are no supports or safety nets in place to provide parents and caregivers with assistance meeting this basic need. Importantly, nearly one-third of mothers who reported diaper need did not report food insufficiency, suggesting that diaper need captured a unique aspect of material hardship and a specific experience of poverty. Recent strategies to address diaper need include efforts by the White House to increase donations of diapers to the National Diaper Bank Network and to create a new Community Diaper Program that will allow nonprofit organizations serving low-income families to purchase diapers at a reduced price. ${ }^{30}$ In addition, diapers are exempt from sales tax in seven states, and some states, such as California, have attempted to pass legislation to provide purchasing assistance for diapers to families participating in state welfare and childcare programs. ${ }^{31,32}$

\section{Limitations and future directions}

This study is cross-sectional, limiting the ability to make casual assumptions about demonstrated associations. For example, does poor mental health contribute to diaper need, or does diaper need contribute to poor 
mental health? The measure of diaper need used in this study has not been validated. However, the measure was developed with expert input and pilot tests $(n=46)$ of its face validity and acceptability with low-income mothers. Potential confounding variables in the association between maternal mental health and diaper need were limited to those assessed on the needs assessment, and some potential confounders such as child physical or mental health, child age, and maternal postpartum depression were not included.

Future research should continue to consider material hardship, including diaper need, as a pathway by which poverty affects the mental health of mothers. The method developed to assess diaper need for this study can be easily employed in future investigations. The association between maternal depressive symptoms and diaper need found in this study needs to be replicated in additional studies that account for important demographic characteristics and other risk factors that may confound or moderate this association. Future studies would benefit from a larger sample size and a longitudinal design.

\section{Conclusion}

Results from this study establish diaper need as a form of material hardship among low-income women and as a potential risk factor for moderate to high maternal depressive symptoms. Importantly, diaper need is malleable and amenable to both public health and public policy interventions. Inclusion of diapers in interventions designed to address maternal mental health may be a way to mitigate the negative emotional consequences of diaper need and promote equity in mental health outcomes among low-income women.

\section{Acknowledgments}

We would like to thank Joanne Goldblum and Alison Weir, The National Diaper Bank Network; Janet Alfano, The Diaper Bank; and Kia Levey, Heather Howell, Natasha Rivera-LaButhie, and Cerella Craig, The New Haven Mental Health Outreach for Mothers Partnership. All phases of this study were supported by K12 DA031050 (M.V.S.) and the U.S. Department of Health and Human Services, Office of Women's Health grant 1CCEWH111021 (M.V.S.).

\section{Author Disclosure Statement}

Ms. Austin has no conflicts of interest to report. Dr. Smith is a board member of the National Diaper
Bank Network and Huggies/Kimberly Clark is a sponsor of that organization.

\section{References}

1. DeNavas-Walt C, Proctor BD. Income and Poverty in the United States: 2014 Current Population Reports. 2015. Available at www.census.gov/ content/dam/Census/library publications/2015/demo/p60-p252.pdf Accessed January 4, 2017.

2. Beeber LS, Perreria KM, Schwartz T. Supporting the mental health of mothers raising children in poverty: how do we target them for intervention studies? Ann N Y Acad Sci. 2008;1136:86-100.

3. Muntaner C, Eaton WW, Miech R, et al. Socioeconomic position and major mental disorders. Epidemiol Rev. 2004;26:53-62.

4. Sareen J, Afifi TO, McMillan KA, et al. Relationship between household income and mental disorders: findings from a population-based longitudinal study. Arch Gen Psychiatry. 2011;68:419-427.

5. Hall LA, Williams CA, Greenberg RS. Supports, stressors, and depressive symptoms in low-income mothers of young children. Am J Public Health. 1985;75:518-522.

6. Olson AL, DiBrigida LA. Depressive symptoms and work role satisfaction in mothers of toddlers. Pediatrics. 1994;94:363-367.

7. Lanzi RG., Pascoe JM, Keltner B, et al. Correlates of maternal depressive symptoms in a national head start program sample. Arch Pediatr Adolesc Med. 1999;153:801-807.

8. Kahn RS, Wise PH, Kennedy BP, et al. State income inequality, household income, and maternal mental and physical health: cross sectional national survey. BMJ. 2000;321:1311-1315.

9. Beeghly $\mathrm{M}$, Olson $\mathrm{KL}$, Weinberg $\mathrm{MK}$, et al. Prevalence, stability, and sociodemographic correlates of depressive symptoms in black mothers during the first 18 months postpartum. Matern Child Health J. 2003;7:157-168

10. Harrington AR, Greene-Harrington CC. Healthy start screens for depression among urban pregnant, postpartum and interconceptional women. J Natl Med Assoc. 2007;99:226-231.

11. Gershoff E, Raver C, Aber J, et al. Income is not enough: incoporating material hardship into models of income associations with parenting and child development. Child Dev. 2007;78:70-95.

12. Heflin CM, Iceland J. Poverty, material hardship, and depression. Soc Sci Q. 2009;90:1051-1071.

13. Kiernan KE, Huerta MC. Economic deprivation, maternal depression, parenting and children's cognitive and emotional development in early childhood. Br J Sociol. 2008;59:783-806.

14. Reading R, Reynolds S. Debt, social disadvantage and maternal depression. Soc Sci Med. 2001;53:441-453.

15. Manuel Jl, Martinson ML, Bledsoe-Mansori SE, et al. The influence of stress and social support on depressive symptoms in mothers with young children. Soc Sci Med. 2012;75:2013-2020.

16. Heflin CM, Siefert K, Williams DR. Food insufficiency and women's mental health: findings from a 3-year panel of welfare recipients. Soc Sci Med. 2005;61:1971-1982.

17. Siefert K, Finlayson TL, Williams DR, et al. Modifiable risk and protective factors for depressive symptoms in low-income African American mothers. Am J Orthopsychiatry. 2007;77:113-123.

18. Smith MV, Kruse A, Weir A, et al. Diaper need and its impact on child health. Pediatrics. 2013;132:253-259.

19. Raver C, Letourneau N, Scott J, et al. Huggies ${ }^{(B)}$ Every Little Bottom Study: Diaper need in the U.S. and Canada. 2010. Available at www.huggies.com/assets/huggies-2010-every-little-bottom-study.PDF Accessed June 30, 2014.

20. Radloff LS. The CES-D scale: a self-report depression scale for research in the general population. Appl Psychol Meas. 1977:1385-1401.

21. Felitti VJ, Anda RF, Nordenberg D, et al. Relationship of childhood abuse and household dysfunctions to many of the leading causes of death in adults: The Adverse Childhood Experiences (ACE) Study. Am J Prev Med. 1998;14:245-258.

22. United States Department of Agriculture (USDA). U.S. Household Food Security Survey Module: Three-Stage Design, with Screeners. United States Department of Agriculture, Economic Research Service. 2012. Available at www.ers.usda.gov/datafiles Food_Security_in_the_United States/Food_Security_Survey_Modules/hh2012.pdf Accessed June 30, 2014. 
23. Murray L, Cooper PJ. Effects of postnatal depression on infant development. Arch Dis Child. 1997;77:99-101.

24. Campbell SB, Matestic $P$, Von Stauffenberg $C$, et al. Trajectories of maternal depressive symptoms, maternal sensitivity, and children's functioning at school entry. Dev Psychol. 2007;43:1202-1215.

25. Campbell SB, Morgan-Lopez AA, Cox MJ, et al. A latent class analysis of maternal depressive symptoms over 12 years and offspring adjustment in adolescence. J Abnorm Psychol. 2009;118:479-493.

26. Feder A, Alonso A, Tang M, et al. Children of low-income depressed mothers: psychiatric disorders and social adjustment. Depress Anxiety. 2009;26:513-520.

27. Adalat S, Wall D, Goodyear H. Diaper dermatitis-frequency and contributory factors in hospital attending children. Pediatr Dermatol. 2007;24:483-488.

28. Sugimura T, Tananari Y, Ozaki Y, et al. Association between the frequency of disposable diaper changing and urinary tract infection in infants. Clin Pediatr. 2009;48:18-20.

29. The National Diaper Bank Network. Diaper Need in American. Available at http://nationaldiaperbanknetwork.org/what-is-diaper-need Accessed February 18, 2017.

30. Munoz C. The Diaper Divide. Available at https://www.whitehouse.gov/ blog/2016/03/10 diaper-divide Accessed January 4, 2017.

31. The National Diaper Bank Network. Does Your State Charge Sales Tax on Diapers? Available at https://diaperbanknetwork.wordpress.com/2012/ 06/29/does-your-state-charge-sales-tax-on-diapers Accessed February 18,2017
32. The National Diaper Bank Network. California Diaper Changes May Include $\$ 50$ Diaper Voucher. Available at http://

nationaldiaperbanknetwork.org/diaperawareness/california-diaperchanges-may-include-50-diaper-voucher Accessed April 12, 2017.

Cite this article as: Austin AE, Smith MV (2017) Examining material hardship in mothers: associations of diaper need and food insufficiency with maternal depressive symptoms, Health Equity 1:1, 127133, DOI: 10.1089/heq.2016.0023.

\section{Abbreviations Used}

ACEs $=$ adverse childhood experiences

CES-D $=$ Center for Epidemiologic Studies Depression

$\mathrm{CMHA}=$ Community Mental Health Ambassador

$\mathrm{IRB}=$ Institutional Review Board

MOMS $=$ Mental Health Outreach for Mothers

SNAP = Supplemental Nutrition Assistance Program

TANF $=$ Temporary Assistance for Needy Families

WIC $=$ Women, Infants, and Children
Publish in Health Equity

Health Equity

Immediate, unrestricted online access

- Rigorous peer review

- Compliance with open access mandates

- Authors retain copyright

- Highly indexed

- Targeted email marketing

liebertpub.com/heq 